\title{
Seletividade do herbicida sulfentrazone em pós- emergência sobre mudas de café recém implantadas
}

Marcelo Ferri Gonçalves ${ }^{1}$

Saul Jorge Pinto de Carvalho

\section{Resumo}

Embora existam vários herbicidas registrados para a cultura do café (Coffea arabica), pouquíssimos possuem seletividade para serem aplicados diretamente sobre as plantas em pós-emergência. Este trabalho foi desenvolvido com o objetivo de avaliar a seletividade do herbicida sulfentrazone para mudas de café, quando aplicado em pós-emergência, após implantação do cafezal. O trabalho foi desenvolvido com mudas de café, cultivar Catuaí Vermelho IAC 144. Foram realizados dois experimentos distintos, sendo o primeiro em 2012 (mudas com 300 dias e 12 pares de folhas) e o segundo em 2013 (mudas com 180 dias e sete pares de folhas). As mudas foram plantadas em vasos de polietileno de $4 \mathrm{~L}$ de capacidade, preenchidos com solo argiloso. Foram avaliados cinco tratamentos, sendo estes: sulfentrazone a 400, 550 e $700 \mathrm{~g} \mathrm{ha}^{-1}$, além das testemunhas inicial e final sem aplicação. 0 estádio fenológico das mudas de café foi um fator determinante quanto à seletividade do sulfentrazone. 0 herbicida possui características seletivas às plantas de cafeeiro em estádio mais avançado de desenvolvimento, com destaque para a dose de $400 \mathrm{~g} \mathrm{ha}^{-1}$, que permitiu crescimento das mudas mais velhas sem redução de massa seca de raízes. Nesse caso houve manifestação inicial de sintomas fitotóxicos, porém com recuperação fisiológica das plantas a partir dos 35 dias após tratamento. Os sintomas mais característicos de fitotoxicidade do sulfentrazone foram observados em plantas mais jovens de cafeeiro.

Palavras-chave: Coffea arabica. Protox. Matocompetição. Controle.

\section{Introdução}

O cultivo do cafeeiro (Coffea arabica L.) possui grande importância para a economia brasileira, principalmente devido às divisas internacionais que proporciona, além da possibilidade de emprego para grande número de trabalhadores (CAIXETA et al., 2008). Atualmente, os principais estados produtores de café no país são: Minas Gerais, Espírito Santo, São Paulo, Bahia, Rondônia e Paraná, correspondendo a mais de $90 \%$ da produção nacional de café (COMPANHIA NACIONAL DE ABASTECIMENTO - CONAB, 2016).

Dentre as diversas culturas perenes cultivadas no Brasil, o café destaca-se por sua sensibilidade à competição exercida pelas plantas daninhas, com reflexos negativos no crescimento das plantas jovens (FIALHO et al., 2012). Segundo Silva e Tomaz (2008), a competição das plantas daninhas com o cafeeiro é mais severa durante a fase de formação da lavoura (primeiro e segundo ano após a implantação) e também nos meses de outubro a março (época das águas), período que coincide com a frutificação do cafeeiro. Sabidamente, o cafeeiro possui crescimento lento quando comparado ao crescimento das plantas daninhas, o que permite que essas exerçam maior competição pelos recursos disponíveis, uma

1 Yara Brasil Fertilizantes S.A., consultor técnico comercial sênior. Ijuí, Rio Grande do Sul, Brasil. marcelo.goncalves@yara.com. Av. Carlos Gomes, 1672, Auxiliadora, Porto Alegre, RS, CEP: 90480-002.

2 Instituto Federal de Educação, Ciência e Tecnologia do Sul de Minas Gerais - Campus Machado, professor doutor. Machado, Minas Gerais, Brasil.sjpcarvalho@yahoo.com.br. Caixa Postal 1054, Machado, MG, CEP: 37750-971. 
vez que a capacidade das plantas infestantes em absorver água e nutrientes é comparativamente maior (TOLEDO; MORAES; BARROS, 1996; DIAS; ALVES; DIAS, 2004; RONCHI; SILVA, 2006).

Além disso, plantas jovens de café são muito sensíveis à interferência das plantas daninhas que crescem na linha de plantio, podendo ter seu crescimento e ciclo reprodutivo comprometidos caso o controle não seja efetuado em tempo hábil (RONCHI; SILVA, 2003). No entanto, controlar plantas daninhas na linha de plantio do café é extremamente complicado, pois o controle manual é dispendioso e, muitas vezes, impossível de ser realizado, devido à escassez de mão de obra e à umidade excessiva do solo; ainda, o controle químico carece de herbicidas seletivos para uso nessa fase da cultura e, também, de tecnologias adequadas à aplicação dos herbicidas não seletivos (RONCHI; SILVA; FERREIRA, 2001).

Mesmo existindo vários herbicidas registrados para a cultura do café, poucos possuem seletividade total para serem aplicados diretamente sobre as plantas, em pós-emergência. Dentre os herbicidas com registro para o café, encontra-se o sulfentrazone. Trata-se de um herbicida de ação tanto em pré como em pós-emergência, sendo o seu mecanismo de ação classificado como inibidor da protox (protoporfirinogênio oxidase). A seletividade desse herbicida às plantas está supostamente relacionada à capacidade que as culturas possuem em metabolizá-lo rapidamente (ARRUDA; LOPES; BACARIN, 1999; CARVALHO; LÓPEZ-OVEJERO, 2008).

Assim sendo, este trabalho foi desenvolvido com o objetivo de avaliar a seletividade do herbicida sulfentrazone quando aplicado em pós-emergência sobre mudas de café em estádio de recém implantação.

\section{Material e métodos}

Foram desenvolvidos dois experimentos distintos no viveiro experimental do Instituto Federal de Educação, Ciência e Tecnologia do Sul de Minas Gerais - Campus Machado (2141' 54.46"S e $21^{\circ} 41^{\prime} 54.46^{\prime \prime S}$ a $860 \mathrm{~m}$ de altitude), o primeiro entre setembro e dezembro de 2012 e o segundo entre março e junho de 2013.

As mudas de café (Coffea arabica L.), cultivar Catuaí Vermelho IAC 144, foram adquiridas de viveiro comercial. Após aquisição, as mudas foram plantadas em vasos de polietileno, com capacidade para 4 litros de substrato. Nos experimentos foi utilizado solo de textura argilosa (47 \% de areia, $40 \%$ de argila e $13 \%$ de silte), peneirado, coletado no próprio Campus, cuja composição química está apresentada na Tabela 1. O solo foi previamente corrigido para outras culturas, atendendo às necessidades do cafeeiro (MALAVOLTA, 2006).

Tabela 1. Propriedades químicas do solo utilizado nos experimentos. Machado (MG), 2012/13.

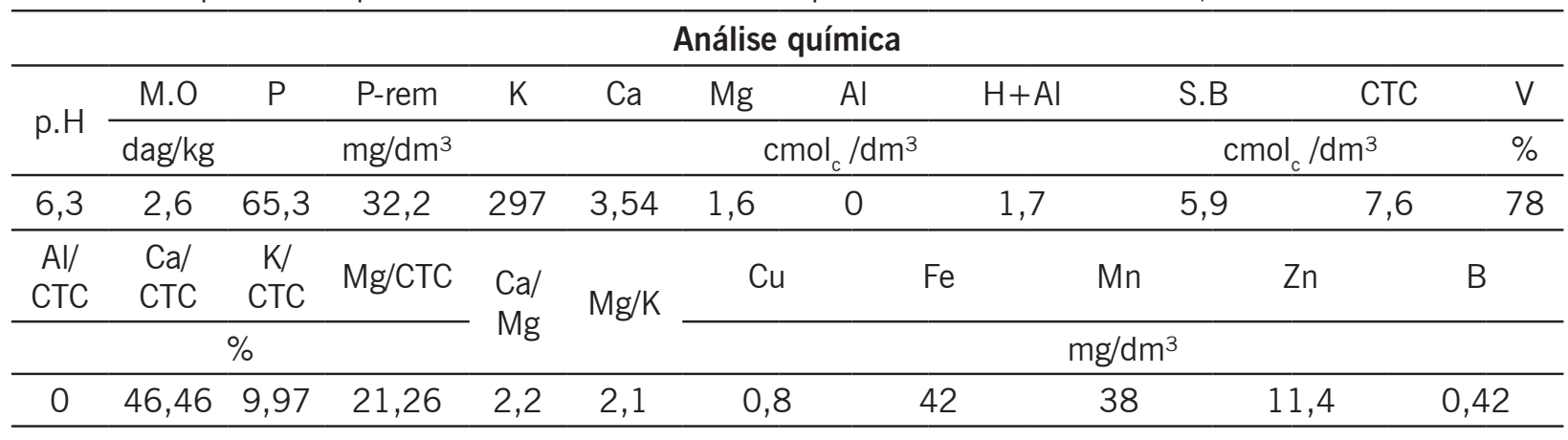

Métodos de extração: pH: água; M.O.: S. Sulfurosa; P,K,Cu,Fe,Mn,Zn: Mehlich-I; P-rem: $\mathrm{CaCl}_{2}$; Ca, $\mathrm{Mg}, \mathrm{Al}: \mathrm{KCl}$; $\mathrm{H}+\mathrm{Al}$ : Tampão SMP; B: Água Quente.

Fonte: Laboratório de Análise de Solos, IFSULDEMINAS - Campus Machado - MG. 
Após transplante para os vasos, as plantas foram cultivadas em ausência de estresse hídrico e mantidas durante quinze dias em ambiente sombreado (sombrite), com 50 \% de luminosidade, para aclimatação e adaptação ao ambiente. Após esse período, foram transferidas para sol pleno por mais quinze dias, quando então foram submetidas aos tratamentos com herbicidas. Foram avaliados cinco tratamentos, sendo estes: sulfentrazone a 400, 550 e $700 \mathrm{~g} \mathrm{ha}^{-1}$, além de testemunha colhida no dia da aplicação e testemunha sem aplicação coletada ao final do experimento, junto dos tratamentos com herbicidas.

Em ambos os experimentos o delineamento experimental foi o de blocos ao acaso, considerando-se como bloco a padronização do porte das mudas. Cada unidade experimental foi constituída por um vaso, contendo uma muda de café. O primeiro experimento, realizado em 2012, foi instalado com sete repetições, utilizando mudas com doze pares de folhas definitivas e cerca de 300 dias após semeadura. O experimento desenvolvido em 2013 foi instalado com seis repetições, utilizando mudas com média de sete pares de folhas definitivas e, aproximadamente, 180 dias após semeadura.

Para todas as pulverizações, foi utilizado pulverizador costal de precisão, pressurizado por $\mathrm{CO}_{2}$, operando à pressão constante de $2,5 \mathrm{kgf} \mathrm{cm}^{-2}$, acoplado à barra com um bico do tipo leque 110.02 , distanciado a uma altura de 0,40 m das plantas, pulverizando-se o equivalente a 200 litros ha-1 de calda. A temperatura, vento e umidade relativa do ar, no momento da aplicação, foram aferidas no início e término do procedimento (Tabela 2). Em todas as aplicações foi utilizada água deionizada como veículo. As temperaturas máximas e mínimas referentes ao período e local de desenvolvimento dos experimentos estão apresentadas na Figura 1.

Tabela 2. Dados meteorológicos registrados no momento das aplicações. Machado, 2012/13

\begin{tabular}{lcccc}
\hline \multirow{2}{*}{ Dados Meteorológicos } & \multicolumn{3}{c}{ Ano } \\
\cline { 2 - 5 } & \multicolumn{2}{c}{2012} & \multicolumn{2}{c}{$\mathbf{2 0 1 3}$} \\
\hline \multicolumn{1}{c}{ Data } & 29/out & Inicial & Final \\
\hline Período & Inicial & Final & $14: 35$ & $14: 47$ \\
Horário da aplicação & $14: 05$ & $14: 15$ & 26,5 & 25,4 \\
Temperatura ( $\left.{ }^{\circ} \mathrm{C}\right)$ & 39,0 & 38,2 & 70,5 & 73,0 \\
Umidade relativa do ar (\%) & 42,0 & 43,6 & 0,5 & 0,0 \\
Velocidade do vento (m/s) & 1,0 & 1,0 & & \\
\hline
\end{tabular}

Fonte: Elaborada pelos autores (coletado com anemômetro e termo-higrômetro no momento das aplicações).

Para ambos os experimentos, foram feitas avaliações visuais da toxicidade dos herbicidas às plantas de café aos 7, 14, 21, 28 e 35 dias após aplicação dos tratamentos (DAT). Para o experimento de 2012, realizou-se avaliação também aos 45 DAT. Para tanto, foram atribuídas notas percentuais de fitotoxicidade em relação à testemunha (sem aplicação), sendo zero para ausência de sintomas e 100 para morte das plantas.

No experimento desenvolvido em 2012, aos 35 e 45 DAT, foi avaliado o teor de clorofila das plantas de café com auxílio do clorofilômetro modelo SPAD 502 (MINOLTA, 1989). No experimento realizado no ano de 2013, os valores foram observados aos 28 e 35 DAT. Para a avaliação, foram mensurados na superfície do limbo foliar os teores de clorofila, sendo medidos em três folhas velhas e duas folhas jovens por planta. Após esse procedimento, foi realizada a colheita total do experimento. Após retirar a parte aérea das parcelas, cortando-se as plantas rente ao solo, o sistema radicular foi lavado em água corrente até a total retirada do solo. Em seguida, para determinação da biomassa 
seca, todo o material foi acondicionado em estufa de circulação forçada de ar, a $70{ }^{\circ} \mathrm{C}$, até massa constante.

Todos os dados foram submetidos à aplicação do teste $F$ na análise da variância, com auxílio do programa Sisvar (FERREIRA, 2000). Em seguida, foi utilizado o teste de Tukey para comparação dos dados e emprego de regressões polinomiais. Todos os testes foram realizados com nível de $5 \%$ de significância.

Figura 1. Temperaturas máximas e mínimas diárias para o período e local de desenvolvimento do experimento. A - Segundo semestre de 2012; B - Primeiro semestre de 2013. Machado (MG), 2012/2013
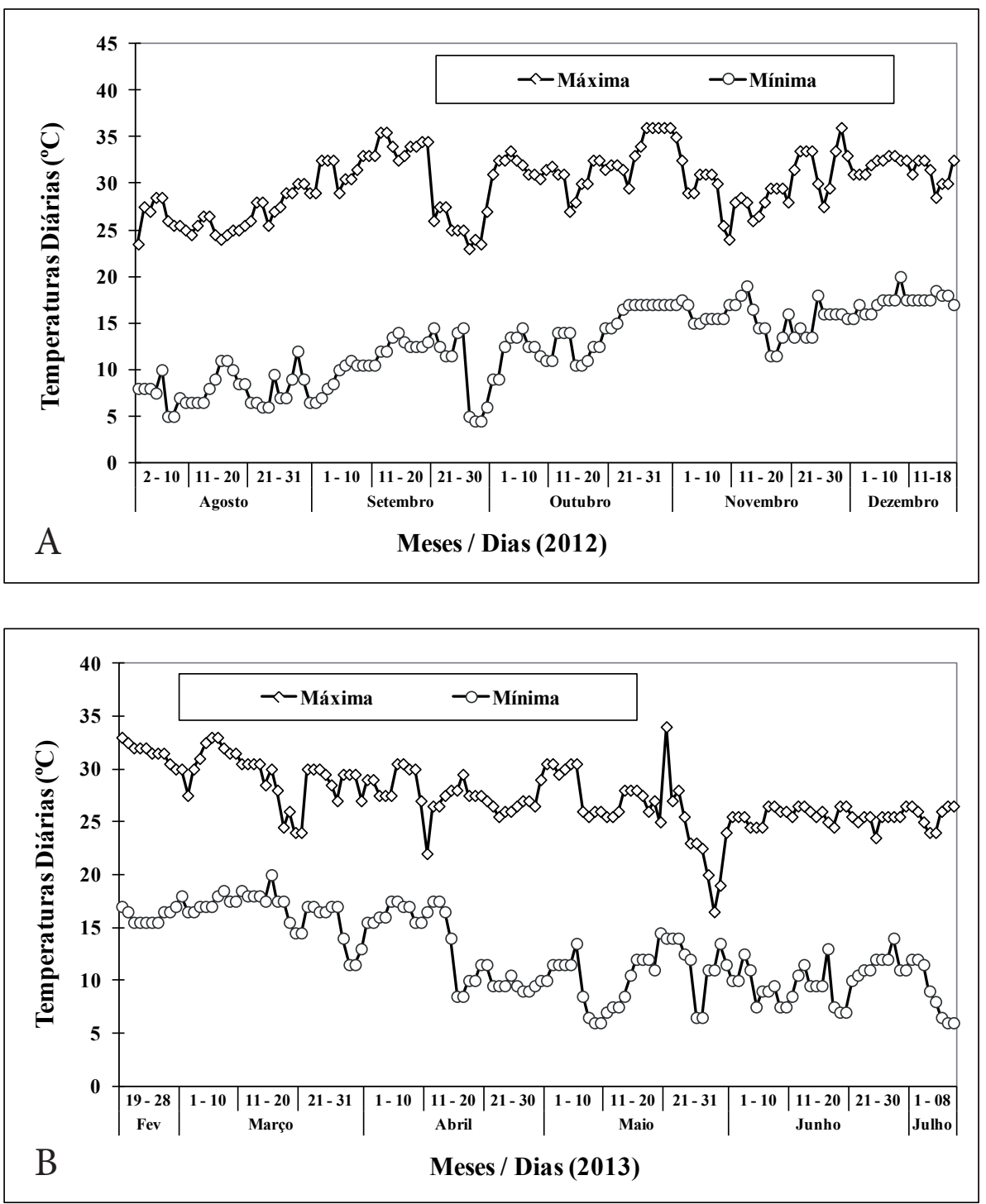

Fonte: Estação Meteorológica instalada no Campus Machado - MG.

\section{Resultados e discussão}

Na Figura 2, estão apresentados os dados de fitotoxicidade do sulfentrazone às mudas de café, em todas as datas de avaliação, para o experimento realizado em 2012. Aos 7 DAT, observaram-se baixos níveis de intoxicação, em que o incremento da dose do produto resultou em maior intoxicação das plantas. Os sintomas já foram evidentes nessa avaliação e, dentre os blocos, foram mais expres- 
sivos nas mudas com estádio fenológico inferior, caracterizados por manchas necróticas nas regiões periféricas da folha, além de pontuações com os mesmos sintomas dispersos na superfície do limbo foliar. Resultados similares foram observados por Ronchi e Silva (2003) em mudas de café, em que o sulfentrazone causou necrose nas folhas mais novas e as que surgiram posteriormente também manifestaram o mesmo sintoma. O sulfentrazone é um herbicida inibidor da protox (HESS e WELLER, 2000), o que explica as necroses observadas. Aos 14 DAT, foram verificados os maiores valores de fitotoxicidade, porém não ultrapassando $20 \%$ de intoxicação.

Figura 2. Fitotoxicidade do herbicida sulfentrazone a mudas de Coffea arabica L., em diferentes datas de avaliação. Machado, 2012.

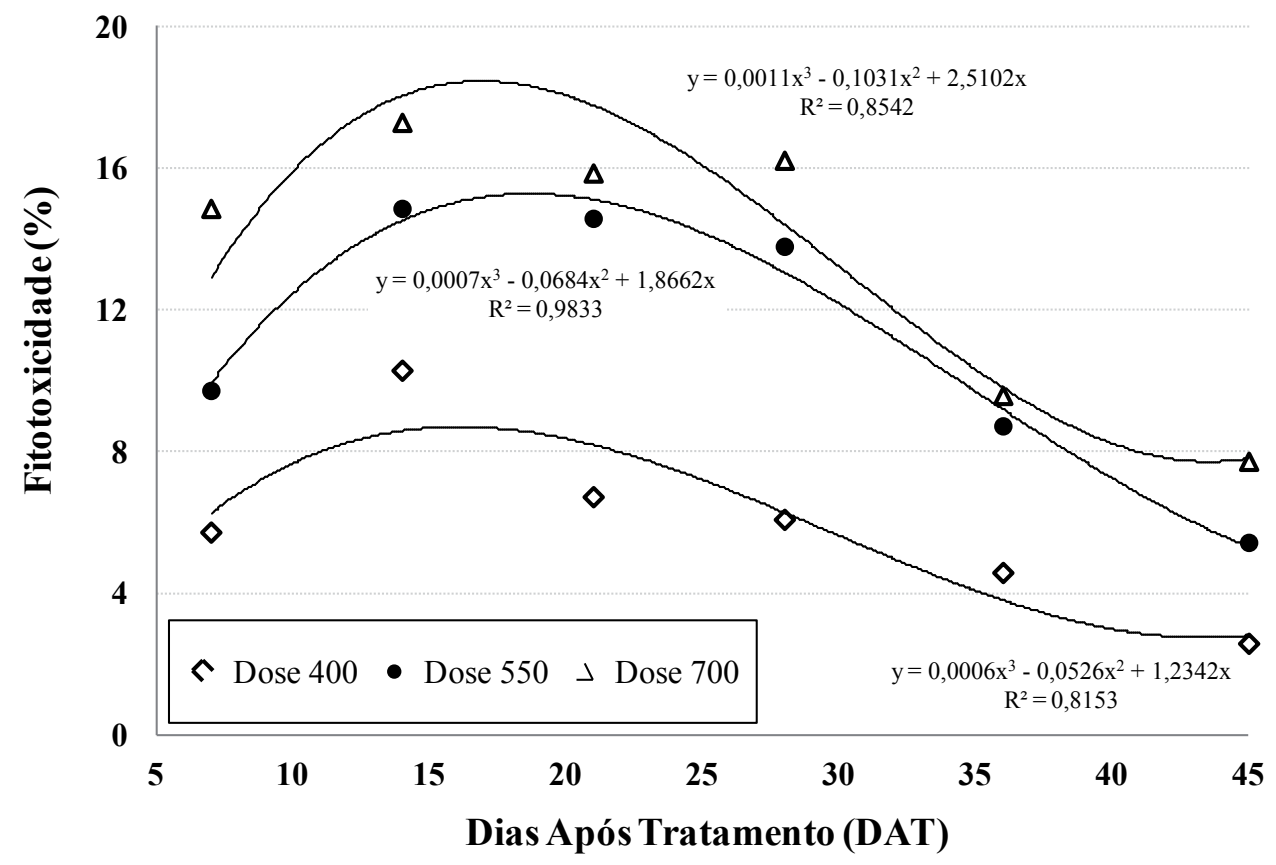

Fonte: Elaborada pelos autores.

Segundo Carvalho e López-Ovejero (2008), em geral, a tolerância natural de espécies vegetais aos herbicidas inibidores da protox está relacionada com o rápido metabolismo do herbicida nas plantas (comumente via citocromo P-450 ou conjugação com glutathiona), porém também pode haver menor absorção foliar ou radicular, menor translocação, super-produção ou insensibilidade enzimática e sequestração do herbicida.

Foram observados em cultivares de soja diferentes níveis de tolerância ao sulfentrazone aplicado em pré-emergência da cultura (DAYAN et al., 1997; SWANTEK; SNELLER; OLIVER, 1998). Dayan et al. (1997) não encontraram diferenças na absorção e translocação de ${ }^{14} \mathrm{C}$-sulfentrazone, e pequenas diferenças no metabolismo foram observadas até três horas após os tratamentos, comparando cultivares sensíveis e tolerantes. Esses autores relataram que a tolerância está associada à capacidade dos cultivares tolerantes ao herbicida em metabolizar o estresse peroxidativo, por meio de sistemas antioxidantes (FINCKH; KUNERT, 1985). Velini et al. (2005) verificaram que configurações da enzima protox ou promotores que permitiriam diferentes níveis de expressão podem permitir genótipos que sejam mais tolerantes aos herbicidas que atuam na inibição dessa enzima.

Nesse sentido, a partir dos 14 DAT, foi observada queda gradativa nos valores de intoxicação das plantas, mostrando a capacidade das mudas de café em metabolizar a molécula do herbicida (Figura 2). Resultado semelhante foi observado para a biomassa seca do cafeeiro (Tabela 3), cujas plantas foram submetidas aos tratamentos com 400 e $550 \mathrm{~g} \mathrm{ha}^{-1}$ e alcançaram maiores valores de 
biomassa de parte aérea que a testemunha inicial, enquanto os tratamentos com 400, 550 e $700 \mathrm{~g}$ ha-1 alcançaram valores similares à testemunha final, colhida aos 45 DAT.

Quanto aos valores de biomassa do sistema radicular e total, observou-se que os tratamentos com 550 e $700 \mathrm{~g} \mathrm{ha}^{-1}$ de sulfentrazone provocaram redução da massa seca quando comparados à testemunha final (Tabela 3). Essa constatação, possivelmente, foi consequência da pulverização e persistência do sulfentrazone no substrato dos vasos, após aplicação em área total. O sulfentrazone é uma molécula do grupo das fenil-triazolinonas com elevado efeito residual no solo (MELO et al., 2010; MONQUERO et al., 2010; LOURENÇO; CARVALHO, 2015).

Tabela 3. Biomassa seca da parte aérea, sistema radicular e total das mudas de Coffea arabica L. submetidas à aplicação de diferentes doses de sulfentrazone. Machado, 2012.

\begin{tabular}{cccc}
\hline $\begin{array}{c}\text { Sulfentrazone } \\
\text { ( } \mathbf{g} \text { i.a. } \text { ha }^{-1} \text { ) }\end{array}$ & Parte aérea & $\begin{array}{c}\text { Biomassa Seca } \mathbf{~ g ) ~} \\
\text { Sistema radicular }\end{array}$ & Total \\
\hline Testemunha Final & $13,92 \mathrm{a}$ & $6,59 \mathrm{a}$ & $20,51 \mathrm{a}$ \\
400 & $13,26 \mathrm{a}$ & $5,72 \mathrm{ab}$ & $18,99 \mathrm{ab}$ \\
550 & $12,25 \mathrm{a}$ & $3,68 \mathrm{bc}$ & $16,08 \mathrm{bc}$ \\
700 & $11,25 \mathrm{ab}$ & $3,23 \mathrm{c}$ & $14,48 \mathrm{~cd}$ \\
Testemunha inicial & $8,29 \mathrm{~b}$ & $2,34 \mathrm{c}$ & $10,63 \mathrm{~d}$ \\
\hline CV (\%) & 17,28 & 35,05 & 16,33 \\
DMS 5\% & 3,21 & 2,38 & 4,15 \\
\hline
\end{tabular}

Médias seguidas por letras iguais minúsculas na coluna não diferem entre si pelo Teste de Tukey $(p<0.05)$ Fonte: Elaborada pelos autores.

O equipamento Minolta SPAD-502, que mede a intensidade da coloração verde das folhas, tem sido utilizado na quantificação de clorofilas, caracterizando-se pela rapidez, simplicidade e, principalmente, por possibilitar uma avaliação não destrutiva do tecido foliar (RAMOS; MONNERAT; PINHO, 2013). Visto que a enzima protox está presente na rota de síntese da clorofila (MEROTTO JÚNIOR; VIDAL, 2001), optou-se por realizar a quantificação do índice SPAD (MINOLTA, 1989) a fim de observar a influência provocada pelo herbicida nos níveis de clorofila da planta.

Conforme observado na Tabela 4, aos 35 DAT, não houve diferença quanto aos valores no índice SPAD. Porém, aos 45 DAT, foi constatado na testemunha valor significativamente menor do que nas plantas em que foi aplicado o herbicida. Como citado previamente, um dos sintomas característicos do sulfentrazone é o escurecimento do limbo foliar, possivelmente interferindo na leitura da intensidade de coloração verde das folhas, realizadas pelo SPAD.

Tabela 4. Índice SPAD avaliado no limbo foliar das mudas de Coffea arabica L., obtidos com auxílio do aparelho Minolta SPAD-502. Machado, 2012

\begin{tabular}{ccc}
\hline Tratamento & \multicolumn{2}{c}{ Índice SPAD } \\
\hline Sulfentrazone & 35 & 45 \\
\cline { 2 - 3 }$\left(\mathrm{g} \mathrm{i.a.} \mathrm{ha}^{-1}\right)$ & \multicolumn{2}{c}{ Dias após o tratamento (DAT) } \\
\hline Testemunha & $46,57 \mathrm{a}$ & $49,51 \mathrm{~b}$ \\
400 & $50,91 \mathrm{a}$ & $55,28 \mathrm{a}$ \\
550 & $51,34 \mathrm{a}$ & $53,94 \mathrm{ab}$ \\
700 & $50,50 \mathrm{a}$ & $54,81 \mathrm{a}$ \\
\hline CV $(\%)$ & 6,82 & 6,18 \\
DMS 5\% & 5,13 & 4,98 \\
\hline
\end{tabular}

Médias seguidas por letras iguais minúsculas na coluna não diferem entre si pelo teste de Tukey $(p<0.05)$.

Fonte: Elaborada pelos autores. 
No segundo experimento, no ano de 2013, utilizando-se de mudas mais jovens, foram constatados maiores sintomas de fitotoxicidade do herbicida (Figura 3). Esses efeitos de fitotoxicidade também foram observados por Magalhães et al. (2012), quando aplicaram sulfentrazone em área total sobre mudas de cafeeiro. Diferente do que foi observado no experimento realizado em 2012, as plantas não se recuperaram após os 14 DAT (Figura 3), sendo que os maiores níveis de intoxicação foram observados aos 35 DAT, próximos a 30 \% de fitotoxicidade. Nos estudos em campo, MagaIhães et al. (2012) observaram picos de fitotoxicidade do herbicida sulfentrazone aos 53 DAT em mudas recém-transplantadas e aos 36 DAT em mudas com três meses de implantação, elucidando o fato de que mudas de café em estádio mais avançado têm maior poder de metabolização desse herbicida. Não foi constatada diferença nos níveis de fitotoxicidade $(p<0,05)$ entre as doses de sulfentrazone em todas as avaliações realizadas neste segundo experimento.

Figura 3. Fitotoxicidade do herbicida sulfentrazone a mudas de Coffea arabica L., em diferentes datas de avaliação. Machado (MG), 2013

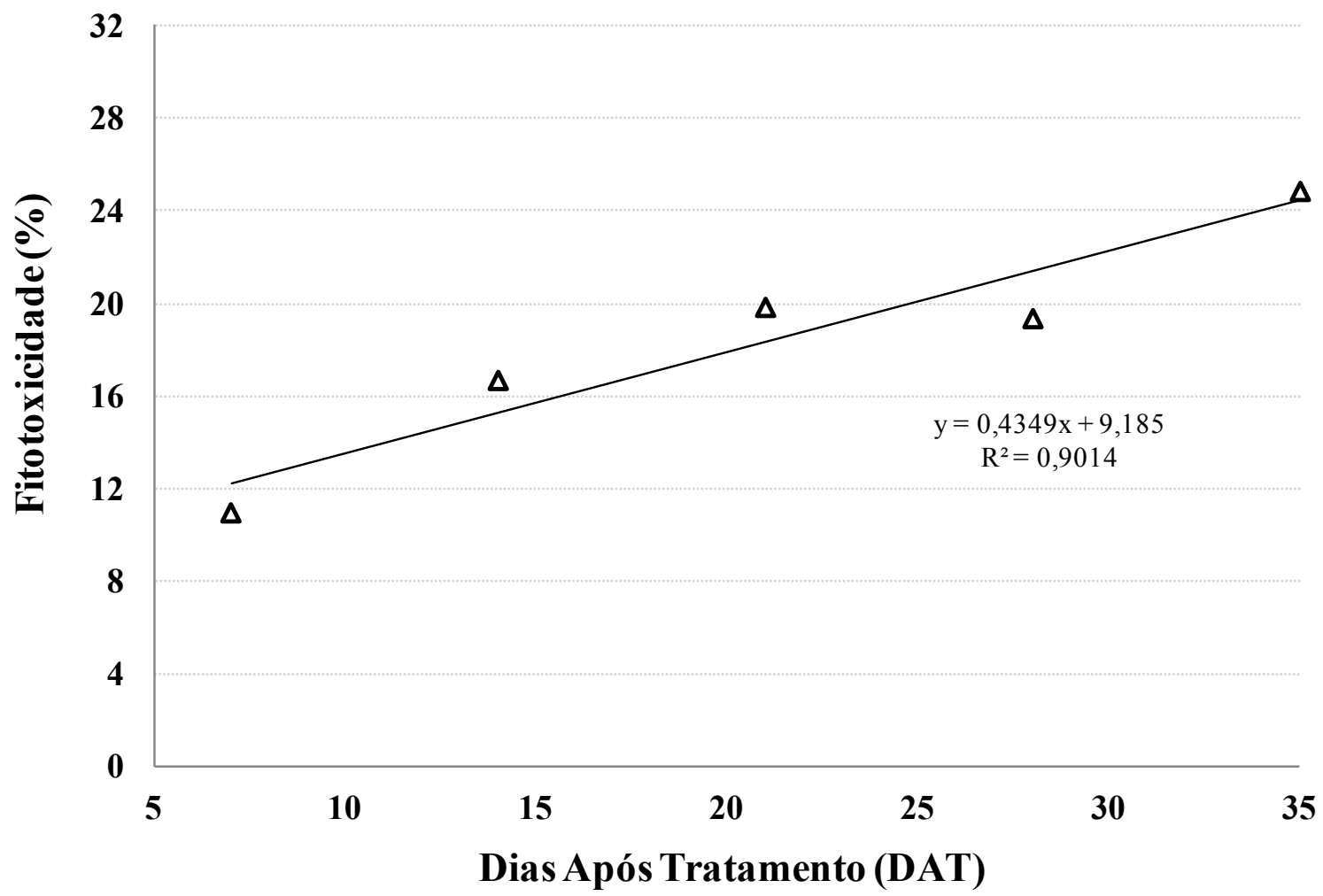

Fonte: Elaborada pelos autores.

Não foram identificadas diferenças em relação aos valores de biomassa total e da parte aérea (Tabela 5), quando os tratamentos foram comparados à testemunha inicial. Fato esse que possivelmente está relacionado à menor temperatura ambiente registrada no período experimental, observada inclusive no dia de aplicação (Tabela 2), que resulta em menor crescimento vegetal. Nazareno et al. (2003) citam que o crescimento do cafeeiro no sudeste brasileiro é reduzido no período frio e seco, e no período quente e chuvoso, é observado rápido crescimento da planta. 
Tabela 5. Biomassa seca da parte aérea, sistema radicular e massa seca total das mudas de Coffea arabica L. após aplicação de diferentes doses de sulfentrazone. Machado (MG), 2013

\begin{tabular}{cccc}
\hline Sulfentrazone & \multicolumn{3}{c}{ Biomassa Seca $(\mathrm{g})$} \\
\cline { 2 - 4 }$\left(\mathrm{g} \mathrm{i.a.} \mathrm{ha-}^{-1}\right)$ & Parte aérea & Sistema Radicular & Total \\
\hline Testemunha & $3,72 \mathrm{a}$ & $2,57 \mathrm{a}$ & $\mathbf{3} \mathrm{a}$ \\
400 & $2,60 \mathrm{a}$ & $2,28 \mathrm{a}$ & $4,88 \mathrm{a}$ \\
550 & $3,71 \mathrm{a}$ & $2,58 \mathrm{a}$ & $6,30 \mathrm{a}$ \\
700 & $3,13 \mathrm{a}$ & $2,50 \mathrm{a}$ & $5,64 \mathrm{a}$ \\
Testemunha inicial & $3,24 \mathrm{a}$ & $0,85 \mathrm{~b}$ & $5,15 \mathrm{a}$ \\
\hline CV $(\%)$ & 31,04 & 15,44 & 20,23 \\
DMS 5\% & 1,83 & 0,59 & 1,97 \\
\hline
\end{tabular}

Médias seguidas por letras iguais minúsculas na coluna não diferem entre si pelo Teste de Tukey $(p<0.05)$ Fonte: Elaborada pelos autores.

Os valores do índice SPAD foram obtidos aos 28 e 35 DAT (Tabela 6). Apenas para os tratamentos com 400 e $550 \mathrm{~g} \mathrm{ha}^{-1}$ foi observada diferença aos 28 DAT. Porém, aos 35 DAT, não houve diferença entre os tratamentos.

Tabela 6. Índice SPAD avaliado no limbo foliar das mudas de Coffea arabica L., obtidos com auxílio do aparelho Minolta SPAD-502. Machado - MG, 2013

\begin{tabular}{ccc}
\hline Tratamento & \multicolumn{2}{c}{ Índice SPAD } \\
\hline \multirow{2}{*}{ Sulfentrazone $\left(\mathrm{g} \mathrm{ha}^{-1}\right)$} & \multicolumn{2}{c}{ Dias após o tratamento (DAT) } \\
\cline { 2 - 3 } & $52,83 \mathrm{ab}$ & $50,23 \mathrm{a}$ \\
\hline Testemunha & $56,08 \mathrm{a}$ & $54,05 \mathrm{a}$ \\
400 & $51,73 \mathrm{ab}$ & $50,25 \mathrm{a}$ \\
550 & $47,33 \mathrm{~b}$ & $48,55 \mathrm{a}$ \\
700 & 9,80 & 15,46 \\
CV (\%) & 8,48 & 13,06 \\
\hline
\end{tabular}

Médias seguidas por letras iguais minúsculas na coluna não diferem entre si pelo Teste de Tukey $(p<0.05)$ Fonte: Elaborada pelos autores.

\section{Conclusões}

O estádio fenológico das mudas de café é um fator determinante quanto à seletividade do sulfentrazone. $O$ herbicida possui características seletivas às plantas de cafeeiro em estádio mais avançado de desenvolvimento, com destaque para a dose de $400 \mathrm{~g} \mathrm{ha}^{-1}$, que permitiu crescimento das mudas sem redução de biomassa seca de raízes. Nesse caso, houve manifestação inicial de sintomas fitotóxicos, porém com recuperação fisiológica das plantas a partir dos 35 DAT. Os sintomas mais característicos de fitotoxicidade do sulfentrazone foram observados em plantas mais jovens de cafeeiro. 


\title{
Sulfentrazone post-emergence selectivity on coffee seedlings after implantation
}

\begin{abstract}
There are several herbicides registered to the coffee (Coffea arabica L.) plantations in Brazil; however, few of them have enough selectivity to be applied directly over the plants in post-emergence. Therefore, this work was developed with the objective of evaluating sulfentrazone selectivity for coffee seedlings, when post-emergence applied, after installing the coffee plantation. The work was developed with coffee seedlings, cultivar Red Catuaí IAC 144. Two distinct trials were developed, the first in 2012 (seedlings with 300 days and twelve pairs of leaves) and the second in 2013 (seedlings with 180 days and seven pairs of leaves). Seedlings were planted in 4L plastic pots, filled with clay soil. Five treatments were evaluated: sulfentrazone at 400, 550 and $700 \mathrm{~g} \mathrm{ha}^{-1}$, besides initial and final check plots without herbicide application. Plants' phenological stage was a determinant factor to sulfentrazone selectivity. The herbicide has selective characteristics to coffee plants in advanced stage of development, with highlights to the rate of $400 \mathrm{~g} \mathrm{ha}^{-1}$, that allowed the growth of older plants without reduction of root dry mass. In this case, there were initial phytotoxic symptoms, but with plant starting to recover 35 days after treatment. The most characteristic symptoms of herbicide phytotoxicity were observed in younger plants of coffee.
\end{abstract}

Keywords: Coffea arabica. Protox. Weed competition. Control.

\section{Referências}

ARRUDA, J. S.; LOPES, N. F.; BACARIN, M. A. Crescimento de plantas de soja em função de doses de sulfentrazone. Planta Daninha, v. 17, n. 4, p. 375-386, 1999.

CAIXETA, G. Z. T.; GUIMARÃES, P. T. G.; ROMANIELLO, M. M. Gerenciamento como forma de garantir a competitividade da cafeicultura. Informativo Agropecuário, v. 29, n. 247, p. 14-23, 2008.

CARVALHO, S. J. P.; LÓPEZ-OVEJERO, R. F. Resistência das plantas daninhas aos herbicidas inibidores da protox (Grupo E). In: CHRISTOFFOLETI, P. J. (Coord.). Aspectos de resistência de plantas daninhas a herbicidas. 3. ed. Piracicaba: HRAC-BR, 2008. p. 69-77.

COMPANHIA NACIONAL DE ABASTECIMENTO (CONAB). Acompanhamento da safra brasileira: café. Dezembro 2015. Disponível em <http://www.conab.gov.br/>. Acesso em: 25 jan. 2016.

DAYAN, F. E.; WEETE, J. D.; DUKE, S. O.; HANCOCK, G. Soybean (Glycine max) cultivar differences in response to sulfentrazone. Weed Science, v. 45, n. 5, p. 634-641, 1997.

DIAS, G. F. S.; ALVES, P. L. C. A.; DIAS, T. C. S. Brachiaria decumbens suppresses the initial growth of coffee. Scientia Agricola. v. 61, n. 6, p. 579-583, 2004.

FERREIRA, D. F. SISVAR: sistema de análise de variância, Versão 3.04, Lavras/DEX, 2000.

FIALHO, C. M. T.; SILVA, A. A.; FARIA, A. T.; TORRES, L. G.; ROCHA, P. R. R.; SANTOS, J. B. Teor foliar de nutrientes em plantas daninhas e de café cultivadas em competição. Planta Daninha, v. 30, n. 1, p. 65-73, 2012. 
FINCKH, B. F.; KUNERT, K. J. Vitamin-C and vitamin-E: an antioxidative system against induced lipid peroxidation in higher plants. Jornal Agricultural and Food Chemistry, v. 33, n. 4, p. 574-577, 1985.

HESS, F. D.; WELLER, S. C. Inhibitors of protoporphyrinogen oxidase: diphenyl ethers and oxadiazon. In: ROSS, M. A.; CHILDS, D. J. Herbicide action. West Lafayette: Purdue University, 2000. p. 225-243.

LOURENÇO, R. C.; CARVALHO, S. J. P. Bioindicator demonstrates high persistence of sulfentrazone in dry soil. Pesquisa Agropecuária Tropical, v. 45, n. 3, p. 326-332, 2015.

MAGAlHÃES, C. E. O.; RONCHI, C. P.; RUAS, R. A. A.; SILVA. M. A. A.; ARAÚJO, F. C.; ALMEIDA, W. L.Seletividade e controle de plantas daninhas com oxyfluorfen e sulfentrazone na implantação de lavoura de café. Planta Daninha, v. 30, n. 3, p. 607-616, 2012.

MAlAVOltA, E. Manual de Nutrição Mineral de Plantas. São Paulo: Editora Agronômica Ceres, 2006. p. 638.

MELO, C. A. D.; MEDEIROS, W. N.; TUFFI SANTOS, L. D.; FERREIRA, F. A.; FERREIRA, G. L.; PAES, F. A. S.; REIS, M. R. Efeito residual de sulfentrazone, isoxaflutole e oxyfluorfen em três solos. Planta daninha, v. 28, n. 4, p. 835-842, 2010.

MEROTTO JÚNIOR, A.; VIDAL, R. A. Herbicidas inibidores da Protox. In: VIDAL, R. A.; MEROTTO JÚNIOR, A. (Ed.). Herbicidologia. Porto Alegre: 2001. p.69-86.

MINOLTA. Chlorophyll meter SPAD-502. Instruction manual. Osaka, Minolta Company, Japan, 1989. 22p.

MONQUERO, P. A.; SILVA, P. V.; SILVA HIRATA, A. C.; TABLAS, D. C.; ORZARI, I. Lixiviação e persistência dos herbicidas sulfentrazone e imazapic. Planta daninha, v. 28, n. 1, p. 185-195, 2010.

NAZARENO, R. B.; OLIVEIRA, C. A. S.; SANZONOWICZ, C.; SAMPAIO, J. B. R.; SILVA, J. C. P.; GUERRA, A. F. Crescimento inicial do cafeeiro Rubi em resposta a doses de nitrogênio, fósforo e potássio e a regimes hídricos. Pesquisa Agropecuária Brasileira, v. 38, n. 8, p. 903-910, 2003.

RAMOS, M. J. M.; MONNERAT, P. H.; PINHO, L. G. R. Leitura SPAD em abacaxizeiro imperial cultivado em deficiência de macronutrientes e de boro. Revista Brasileira Fruticultura, v. 35, n. 1, p. 277-281, 2013 .

RONCHI, C. P.; SILVA, A. A. Effects of weed species competition on the growth of young coffee plants. Planta Daninha, v. 24, n. 2, p. 415-423, 2006.

RONCHI, C. P.; SILVA, A. A.; FERREIRA, L. R. Manejo de plantas daninhas em lavouras de café. Viçosa, MG: Universidade Federal de Viçosa, Departamento de Fitopatologia, 2001. 94 p.

RONCHI, C. P.; SILVA. A. A. Tolerância de mudas de café a herbicidas aplicados em pós- emergência. Planta Daninha, v. 21, n. 3, p. 421-426, 2003.

SILVA, A. A.; TOMAZ, M. A. Manejo integrado de plantas daninhas em lavouras de café. In: TOMAZ, M. A.; AMARAL, J. F. T.; JESUS JUNIOR, W. C.; PEZZOPANE, J. R. M. (Eds.). Seminário para a sustentabilidade da cafeicultura. Alegre: UFES, 2008. p. 251-268. 
SWANTEK, J. M.; SNELLER, C. H.; OLIVER, L. R. Evaluation of soybean injury from sulfentrazone and inheritance of tolerance. Weed Science, v. 46, n. 3, p. 271-277, 1998.

TOLEDO, S. V.; MORAES, M. V.; BARROS, I. Efeito da frequência de capinas na produção do cafeeiro. Bragantia, v. 55, n. 2, p. 317-324, 1996.

VELINI, E. D.; TRINDADE, M. L. B.; ALVES, E.; CATÂNEO, A. C.; MARINO, C. L.; MAIA, I. G.; MORI, E. S.; FURTADO, E. L.; GUERRINI, I. A.; WILCKEN, C. F. Eucalyptus ESTs corresponding to the protoporphyrinogen IX oxidase enzyme related to the synthesis of heme, chlorophyll, and to the action of herbicides. Genetics and Molecular Biology, v. 28, n. 3, p.555-561, 2005.

\section{Histórico editorial:}

Submetido em: 19/04/2015

Aceito em: 26/01/2016

Como citar:

$\underline{A B N T}$

GONÇALVES, M. F.; CARVALHO, S. J. P. de. Seletividade do herbicida sulfentrazone em pós-emergência sobre mudas de café recém implantadas. Revista Agrogeoambiental, Pouso Alegre, v. 9, n. 1, p. 23-33, jan./mar. 2017. DOI: http://dx.doi.org/10.18406/2316-1817v9n12017830

APA

GONÇALVES, M. F. \& CARVALHO, S. J. P. de. (2017). Seletividade do herbicida sulfentrazone em pós-emergência sobre mudas de café recém implantadas. Revista Agrogeoambiental, 9 (1), 23-33. DOI: http://dx.doi.org/10.18406/2316-1817v9n12017830

$\underline{\text { ISO }}$

GONÇALVES, M. F.; CARVALHO, S. J. P. de. Seletividade do herbicida sulfentrazone em pós-emergência sobre mudas de cafér recém implantadas. Revista Agrogeoambiental. 2017, vol. 9, n. 1, pp. 23-33. elSSN2316-1817. DOI: http://dx.doi.org/10.18406/2316-1817v9n12017830

\section{VANCOUVER}

Gonçalves MF, Carvalho SJP. Seletividade do herbicida sulfentrazone em pós-emergência sobre mudas de café recém implantadas. Rev agrogeoambiental. 2017 jan/mar; 9(1): 23-33. DOI: http://dx.doi.org/10.18406/2316-1817v9n12017830 